\title{
PEREMAJAAN FASAD ARSITEKTUR RUKO PECINAN UNTUK MEMPERKUAT CITRA VISUAL PADA KORIDOR SEI RAMPAH
}

\author{
Dwira Nirfalini Aulia ${ }^{1}$, Marisa Hajrina ${ }^{2}$ \\ Program Studi Magister Teknik Arsitektur Fakultas Teknik Universitas Sumatera Utara \\ Jl. Perpustakaan St. J07 Building, Medan, 20155, Indonesia \\ *Email: ${ }^{1}$ dwira_aulia@yahoo.com, ${ }^{2}$ marisahajrina@gmail.com
}

\begin{abstract}
ABSTRAK
Koridor Sei Rampah merupakan jalan lintas Sumatera yang terletak di pusat Kota Sei Rampah. Koridor perdagangan dan jasa ini didominasi oleh deretan ruko pecinan yang dahulunya merupakan kawasan perdagangan rempah-rempah oleh etnis Thionghoa. Hal ini dapat menjadikan ciri khas wajah arsitektur kota pada koridor Sei Rampah. Namun faktanya terdapat beberapa bangunan ruko pecinan yang telah direnovasi, tidak terawat, dan bahkan dibiarkan kosong hingga rusak. Selain itu terdapat pula bangunan ruko - ruko baru bergaya arsitektur modern yang tidak harmonis dengan bangunan lama, fenomena - fenomena fisik tersebut di khawatirkan akan menghilangkan kekhasan visual pada koridor Sei Rampah. Oleh karena itu, penelitian ini bertujuan untuk peremajaan fasad bangunan ruko pecinan sebagai bangunan mixed-use yang dapat menjadikan acuan untuk mengembalikan ciri khas dalam koridor dan untuk mendesain fasad ruko yang baru. Metode yang digunakan pada penelitian ini adalah metode deskriptif kualitatif melalui teknik analisis karakter visual pada bangunan ruko pecinan, yang mengamati unsur-unsur warna, tekstur, pola, style dan skala bangunan. Penelitian ini berupa suatu pedoman yang digunakan untuk mengarahkan kepada pemilik bangunan dalam peremajaan desain fasad bangunan ruko pecinan yang ada di koridor agar tidak menghilangkan citra visual dalam koridor Sei Rampah. Sehingga nantinya mampu menciptakan sebuah koridor dengan deretan bangunan yang harmonis dan menarik.
\end{abstract}

Kata Kunci: Ruko Pecinan, Citra Visual, Koridor.

\section{PENDAHULUAN}

Koridor merupakan sebuah lorong yang terbentuk oleh bangunan, vegetasi dan elemen pembentuk ruang lainnya pada kedua sisi jalan. Keberadaan suatu koridor sebagai pembentuk elemen kota tidak akan lepas dari salah satu faktor yang ada dalam koridor tersebut, seperti fasad yang berupa wajah depan bangunan atau tampak depan bangunan yang ada di sepanjang koridor (Yahya, 2015).

Fasad dapat dianggap sebagai eksterior yang merupakan bagian luar bangunan dan memberikan kesan visual. Oleh karena itu, fasad bangunan meliputi elemen proporsi bukaan, material, warna, skala dan langgam arsitektur (Ardiani dalam Setyowati, dkk, 2014). Hal ini merupakan fenomena psikolgi yang berkaitan dengan tampilan fisik koridor. Sehingga, dapat menimbulkan rasa tertentu yang bersifat emosi dan erat kaitannya dengan makna yang dihadirkan oleh suatu obyek atau lingkungan kepada pengamat (Rizqiyah, 2016).

Dalam sebuah kawasan atau wilayah koridor jalan, ada ciri khusus yang dimiliki oleh segala elemen pembentuknya. Ciri khas yang dimiliki oleh masing-masing koridor dapat membantu masyarakat dalam mengorientasikan dirinya ketika sedang berada di suatu wilayah tertentu. Pentingnya sebuah citra mental yang jelas karena dapat memberikan banyak hal yang sangat penting bagi masyarakatnya seperti kemampuan untuk berorientasi dengan mudah dan cepat disertai perasaan nyaman karena tidak merasa tersesat, identitas yang kuat terhadap suatu tempat, dan keselarasan hubungan dengan tempat-tempat yang lain (Lynch dalam Zahnd 1999). Oleh karena itu, terciptanya sebuah identitas kota, kawasan ataupun wilayah koridor, berawal dari pengaruh terbentuknya 
ruang dalam sebuah perancangan kota dan terus berkembangan.

Berdasarkan perkembangan kota, aspek sejarah mempunyai peranan penting dalam membentuk atau memproduksi morfologi kota. (Mumford dalam Tallo, 2014). Jika ditinjau dari lingkup Kota, koridor jalan lintas Timur Sumatera, memiliki arti penting terhadap sejarah perkembangan dan pembentukan kotanya. Berdasarkan (Kecamatan Sei Rampah Dalam Angka 2016), dahulu koridor ini digunakan sebagai kawasan perdagangan rempah-rempah oleh etnis thionghoa dengan memanfaatkan sungai sebagai jalur transportasinya. Hal ini terlihat dari deretan bangunan pertokoan pecinan yang berada di sepanjang koridor dan menjadi salah satu situs budaya Serdang Bedagai. Banyaknya rempah-rempah yang diperdagangakan pada saat itu membuat kota ini dinamakan sebagai Kota Sei Rampah.

Sebagai koridor perdagangan dan jasa yang terletak di pusat Kota Sei Rampah, koridor ini dipenuhi oleh deretan bangunan ruko lama dengan style arsitektur Cina dan bangunan ruko baru dengan gaya arsitektur modern. Sebagian besar bangunan didominasi oleh ruko pecinan yang masih digunakan pemiliknya untuk berdagang. Bangunan peninggalan pada zaman kolonial ini merupakan ciri khas koridor jalan lintas Sumatera yang mana keberadaan deretan bangunannya adalah cikal bakal perkembangan kota Sei Rampah (http://www. academia.edu, akses:29/12/2016). Namun, deretan bangunan ruko lama yang memiliki nilai historis ini sudah banyak yang tidak terawat dan bahkan cukup memprihatinkan dengan kondisi fisik yang telah rusak. Sehingga tidak menutup kemungkinan jika suatu saat nanti bangunan dengan style arsitektur Cina ini dikhawatirkan akan menghilangkan ciri khas visual pada koridor Sei Rampah, ditambah lagi dengan perkembangan koridor yang mulai bermunculan bangunan ruko baru dengan gaya arsitektur modern.

Oleh karena itu, dari kondisi yang ada maka di perlukannya kajian lebih lanjut terkait peremajaan fasad bangunan ruko lama (pecinan) yang memiliki nilai historis dan acuan untuk mendesain fasad ruko yang baru. Sehingga nantinya hasil dari analisis yang diperoleh dapat memberikan gambaran yang lebih memperkuat citra visual koridor Sei Rampah yang hampir punah (Gambar 1).

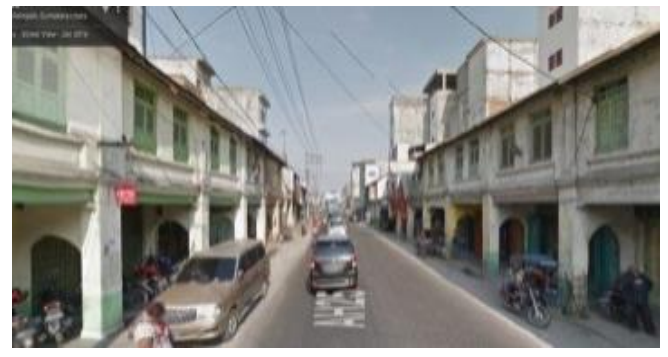

Gambar 1. Ruko Pecinan Koridor Sei Rampah

Berdasarkan Peraturan Daerah Kabupaten Serdang Bedagai (Perda tahun 2013 No.14 Pasal 43 ayat 2), penampilan bangunan gedung yang didirikan dikawasan cagar budaya atau berdampingan dengan bangunan gedung yan dilestarikan, dirancang dengan mempertimbangkan keselarasan kaidah estetika bentuk dan karakteristik dari arsitektur bangunan gedung yang dilestarikan.

\section{METODE PENELITIAN}

Metode penelitian ini, dilakukan dengan metode analisis deskriptif kualitatif, yang mana mendeskripsikan dan mengidentifikasi kondisi eksisting bangunan ruko (pecinan) pada koridor jalan lintas Sumatera Sei Rampah, berdasarkan analisis aspek fisik melalui pengamatan. Analisa dilakukan hanya pada fasad bangunan ruko pecinan yang mengamati unsur-unsur warna, tekstur, pola, style dan skala bangunan, sehingga nanatinya dapat mewujudkan sebuah koridor dengan deretan bangunan yang lebih menarik.

Selain itu data juga diperoleh berdasarkan studi banding proyek sejenis, yang mana proses analisa dapat disimpulkan dengan menghubungkan permasalahan yang ada dengan pedoman melestarikan bangunan historis seperti chinatown, Singapore. Sehingga hasil penelitian ini akan menjadi masukan bagi pemerintah, khususnya pusat kota di koridor lintas Sumatera Sei Rampah sebagai pedoman fasad pada sebuah koridor yang memperhatikan aspek estetika visual dan historis melalui tampilan bangunan ruko yang berarsitektur Cina.

\section{HASIL DAN PEMBAHASAN}

Potensi yang dapat diidentifikasi di koridor Sei Rampah jika ditinjau dari aspek arsitektur adalah koridor Sei Rampah secara arsitektur kota mampu memperkuat ciri khas 
visual dengan gaya arsitektur ruko pecinan sebagai bangunan mixed-use. Analisa dapat diamati dari fasad bangunan ruko pecinan (Gambar 2).

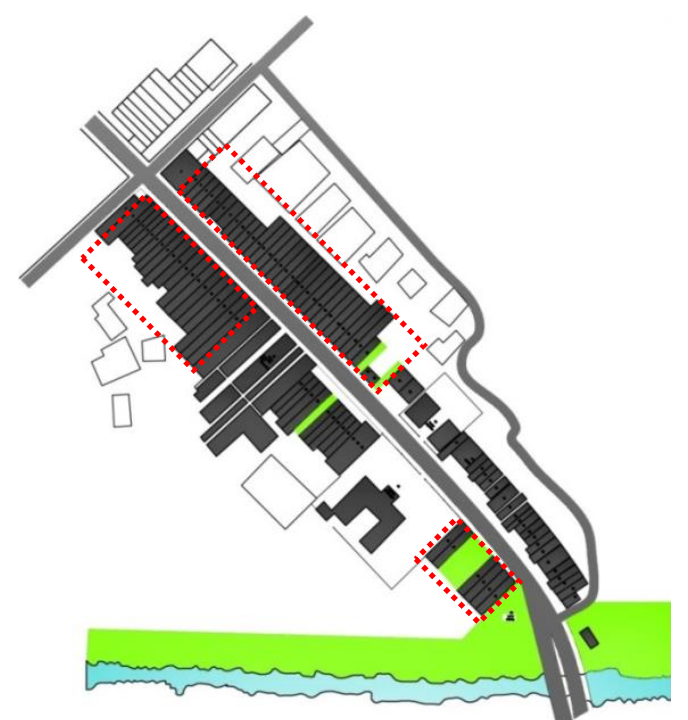

Gambar 2. Peta Eksisting Ruko Lama (Pecinan) Koridor Sei Rampah

\section{Pola dan Style Bangunan}

Renovasi penambahan lantai di atas ruko lama (pecinan) dan perubahan fasad yang tidak mempertimbangkan desain fasad sebelumnya (Gambar 3).

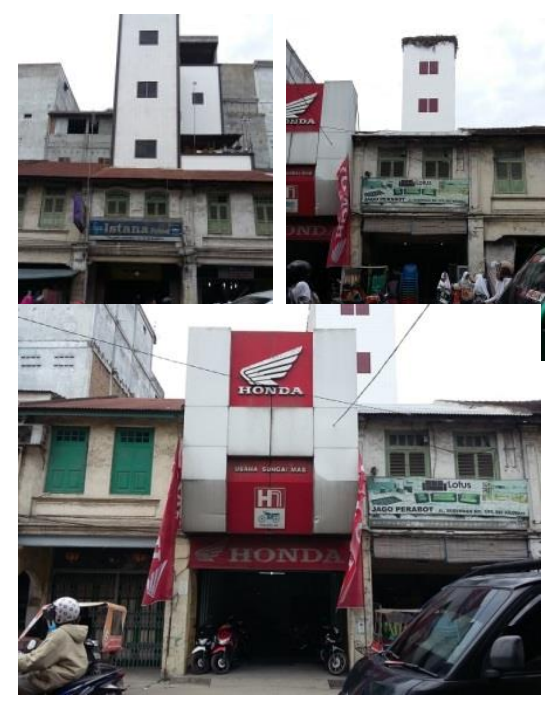

Gambar 3. Kondisi Eksisting Penambahan dan Perubahan Fasad Ruko Lama

Dalam kondisi bangunan ruko lama (pecinan) yang terlampir, terlihat bahwa belum sesuai dalam Peraturan Pemerintah No.36 tahun 2005 tentang bangunan gedung sebagai berikut:
1. Penampilan bangunan mempertimbangkan kaidah-kaidah estetika bentuk, karakteristik arsitektur, dan lingkungan yang ada di sekitarnya.

2. Penampilan bangunan gedung di kawasan cagar budaya, harus dirancang dengan mempertimbangkan kaidah pelestarian.

Adapun Arahan desain fasad pada renovasi penambahan lantai bangunan di atas ruko lama dengan menyesuikan desain fasad sebelumnya (Gambar 4).

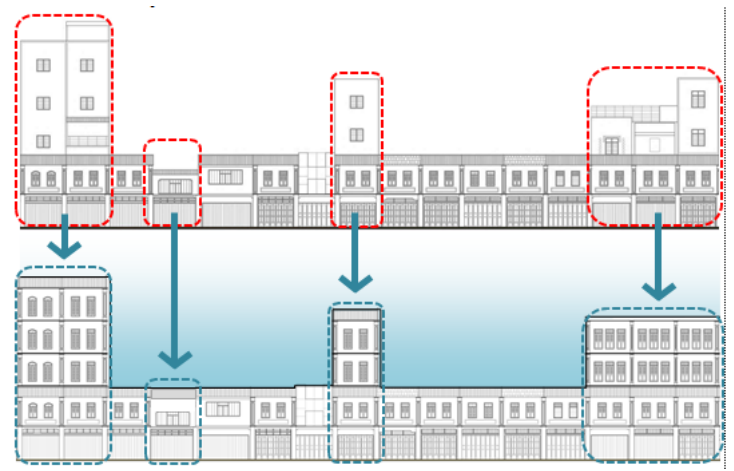

Gambar 4. Hasil Arahan Fasad

Peremajaan bangunan ruko lama yang tidak terawat, dengan memperbaiki jendela yang telah rusak dan memberikan warna baru, agar tidak terkesan kumuh. Memperbaikan/ mengganti material atap, pintu dan memberi warna cat baru pada pintu, dinding dan kolom bangunan ruko, sebagai wujud pelestarian ruko pecinan sebagai citra visual koridor Sei Rampah (Gambar 5).
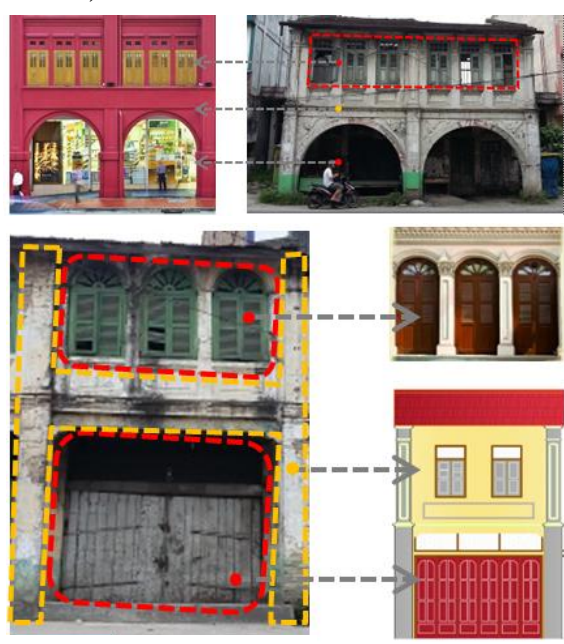

Gambar 5. Peremajaan Fasad Bangunan Ruko Pecinan 
Pada fasad bangunan pecina, terdapat perulangan pola, seperti pada bentuk jendela dan kolom dengan gaya arsitektur Cina sebagai bangunan shophouse (Gambar 6).

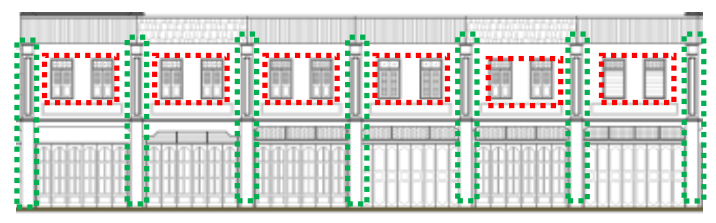

Gambar 6. PolaFasad Bangunan Ruko Pecinan

Dari pola yang ada maka seharus diterapkan pada pola renovasi penambahan lantai, agar masih memberi kesinambungan pola dan style bangunan yang masih mampertahankan kelestarian bangunan ruko pecinan. Berikut gambar studi banding sejenis (Gambar 7).
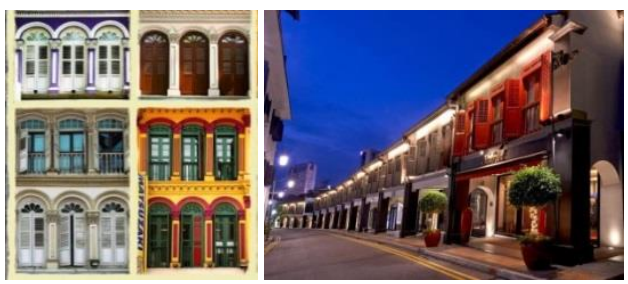

Gambar 7. Shophouse Singapore (Perulangan Pola dengan Gaya Arsitektur Cina)

\section{Warna}

Ruko yang tidak terawat (terkesan kumuh), seperti pengelupasan lapisan dinding/memudarnya warna dinding ruko dan kerusakan fisik bangunan (Gambar 8).
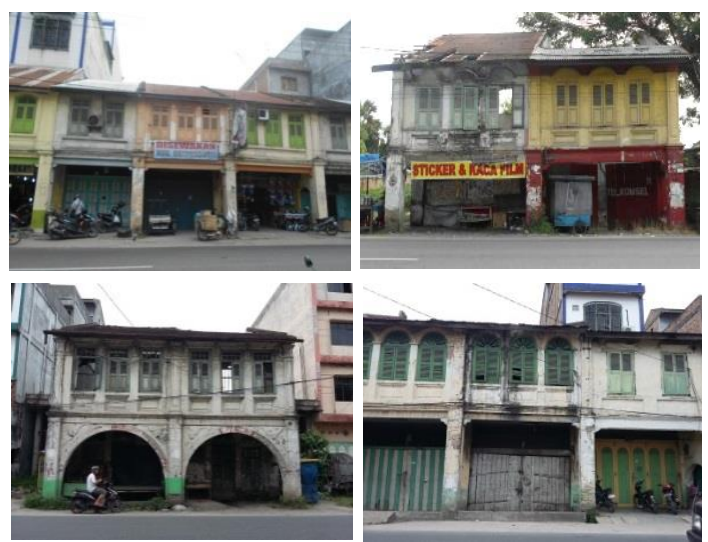

Gambar 8. Kondisi Eksisting Ruko Lama

Perlunya pelestarian bangunan historis yang tidak terawat dengan memberi warna baru pada fasad bangunan agar tidak terkesan kumuh. Misalnya memberikan warna yang sama pada deretan bangunan ruko pecinan (Gambar 9).

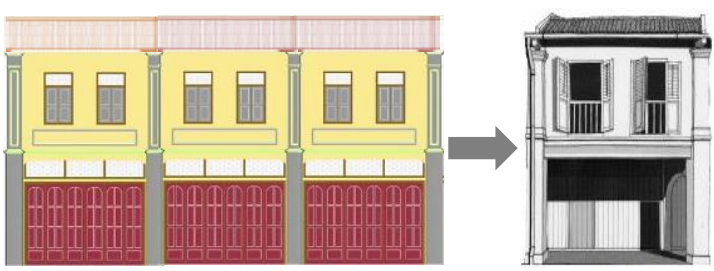

Gambar 9. Warna Fasad Baru

(Koridor Sei Rampah) dan

Shophouse Style (Early 1840 - 1900) Singapore

Penetapan konsep pewarnaan bangunan Shophouse yang berirama menghilangkan kesan monoton pada fasad bangunan yang memiliki kesamaan bentuk bangunan. Berikut ini gambar studi banding sejenis (Gambar 10).
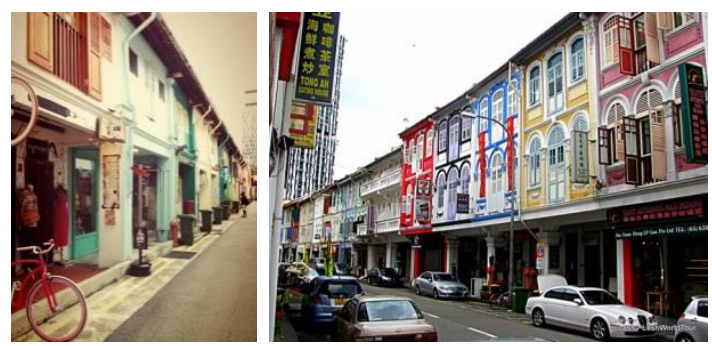

Gambar 10. Warna Fasad Shophouse Style Singapore

\section{KESIMPULAN}

Hasil perencanaan peremajaan fasad bangunan untuk memperkuat citra visual koridor Sei Rampah yang merupakan upaya pengembalian ciri khas koridor terhadap aspek arsitektur kota pada bangunan ruko pecinan, yang mana bangunan tersebut sudah mulai punah dengan tidak terawatnya fisik bangunan dan pertumbuhan bangunan ruko baru yang tidak mempertimbangkan bangunan ruko lama sebagai cikal bakal perkembangan kota Sei Rampah. Oleh karena itu, arahan penetapan fasad bangunan yang dapat diperoleh nantinya mampu menciptakan sebuah koridor dengan deretan bangunan yang memiliki ciri khas ruko lama pecinan sebagai bangunan historis yang harmonis dan menarik, meskipun berdampingan dengan ruko yang baru (dengan arahan fasad yang menyesuaikan bangunan lama). 


\section{Daftar Pustaka}

Badan Pusat Statistik Kabupaten Serdang Bedagai. Kecamatan Sei Rampah Dalam Angka 2016.

http://www.academia.edu/ Pengaruh Arsitektur Terhadap Bangunan Lama Di Sei Rampah.

Peraturan Daerah Kabupaten Serdang Bedagai No.14/P.43(2)/2013. Persyaratann Arsitektur Banguan Gedung.

Peraturan Pemerintah Republik Indonesia No.36/P.22,23/2005. Persyaratan Arsitektur Bangunan Gedung.

Rizqiyah, Fardilla (2016) Arahan Disain Fasad Koridor Jalan Songoyudan untuk Memperkuat Citra Visual pada Area Perdagangan Bersejarah di Surabaya. EMARA Indonesia Journal of Architecture, 2 (1).

Setyowati, Titik Indra, Wulandari, Lisa Dwi, Pamungkas, Sigmawan Tri (2014) Tipologi Fasade Bangunan Di Jalan Kawi Atas Kota Malang. Jurnal Arsitektur universitas Brawijaya.

Tallo, Amandus Jong, Pratiwi, Yulia, Astutik, Indri (2014) Identifikasi Pola Morfologi Kota. Studi Kasus : Sebagian Kecamatan Klojen, Di Kota Malang. Jurnal Perancangan Wilayah dan Kota, 25 (3).

Yahya, M. (2015) Kajian Tata Bangunan dan Lingkungan pada Koridor Jalan Perintis Kemerdekaan Kota Makassar. Jurnal Temu Ilmiah IPLBI.

Zahnd, M. (1999) Perancangan Kota secara Terpadu. Yogyakarta: Penerbit Kanisius. 